\title{
Towards a Process Model for Service Systems
}

\author{
Elisah Lemey and Geert Poels \\ Center for Service Intelligence \\ Faculty of Economics and Business Administration \\ Ghent University \\ Tweekerkenstraat 2, 9000 Gent, Belgium
}

\begin{abstract}
Service Science is a new interdisciplinary approach to the study, design, implementation, and innovation of service systems. However due to the variety in service research, there is no consensus yet about the theoretical foundation of this domain. As a basis for a common understanding of service systems and their interactions, Service Science researchers Spohrer and Kwan proposed the service systems worldview. The ISPAR model was presented as a part of this service systems worldview as a tool for identifying ten possible interaction episodes i.e., the sequences of activities that are undertaken by two interacting service system entities. In this paper we evaluate the use of the ISPAR model as a process model for service systems. We identify the shortcomings of the ISPAR model and propose possible improvements. This analysis leads to the development of a new service process model which is demonstrated through tree different examples.
\end{abstract}

Keywords: Service Science, SSME, service system, service process model, ISPAR model

\section{Introduction}

The research presented in this paper is part of a research project that investigates the theoretical foundation of Service Science which is a new interdisciplinary field that studies the structure and behaviour of service systems. Due to the variety in existing service research (e.g., services marketing, services management, service design, service-oriented computing), there is no consensus yet about which theories and frameworks could serve as a scientific basis for this domain [1-5].

As a starting point for our research, we took the service systems worldview of Spohrer and Kwan [6]. The service systems worldview was proposed as a candidate shared conceptualization for Service Science researchers. The authors use ten foundational concepts to explain the diversity and complexity of service systems.

In [7], we clarified these ten foundational concepts by investigating them from the perspective of established service theories and frameworks. By mapping the proposed service system concepts on the selected service theories and frameworks, we clarified their theoretical foundations, examined their proposed definitions, identified possible conflicting interpretations, discovered their likely relationships and general structure, 
and identified a number of issues that need further discussion and elaboration. One of these issues is that the process orientation of the service systems worldview needs further development. What is currently lacking is a normative view of the process of service system entities interacting to co-create value in a mutually beneficial manner. Not only the outcomes of the interaction deserve attention. Also the way these outcomes are achieved (or not achieved) is something that Service Science researchers wish to study, e.g., in order to measure, analyse, improve or optimize existing service processes, design and test new processes, etc.

To better understand the dynamics of service systems, Spohrer and Kwan proposed the ISPAR model as a normative model of all possible service system interaction outcomes [8]. The ISPAR model shows ten possible interaction episodes, i.e., sequences of activities that are undertaken by two interacting service system entities. Each of these interaction episodes is associated with a particular outcome, which can be a desired or non-desired result of the interactions. Although the ISPAR model can be incorporated into the service systems worldview as a complement of the foundational concepts, we believe that this model has shortcomings when used as a process model for describing the interaction of service system entities. As we will explain, the ISPAR model lacks structure and clarity which is an obstacle in analysing service processes established by two (or more) interacting service system entities.

The aim of this paper is to refine the ISPAR model to a normative process model for service systems. The model is evaluated and four important shortcomings are defined. For each of these shortcomings, we propose a candidate solution. Our research method consisted of comparing the ISPAR model with two established service process models or frameworks which serve as a good basis for the comparison but are in itself incomplete with respect to their coverage of possible interaction episodes between service system entities. We identified which elements from these alternative models or frameworks can be incorporated to further refine and extend the ISPAR model. Next, we proposed a new service process model for Service Science that meets these characteristics. The model is designed as an Event-driven Process Chain (EPC). As it is largely based on the ISPAR model, it includes all the originally proposed interaction episodes. However, it also includes some new elements which should serve as an answer to the identified shortcomings.

Our contribution to the emerging research area of Service Science is twofold. First, an EPC is presented as an improved service process model. This model is aimed at facilitating the presentation and discussion of service processes. It should enable academics and professionals to make a thorough analysis of service processes by modeling them using our normative model as a reference. Second, this paper is an effort to integrate the loosely coupled elements of the service systems worldview into a more coherent and consistent theory. We believe that the extension of the service systems worldview with a normative service process model is beneficial for the further development of Service Science.

Section 2 gives a thorough description of the ISPAR model as proposed by Spohrer and Kwan. In section 3 we evaluate the model by highlighting the most important shortcomings of the model. Section 4 presents possible solutions for these shortcomings. Section 5 then redefines the ISPAR model by using an EPC 
representation. Next, we demonstrate the new service process model in section 6 . Finally, section 7 presents a conclusion and future work.

\section{The Service Systems Worldview}

In [7] we investigated the proposed foundational concepts of the service system worldview from the perspective of established service theories and frameworks used in service marketing, service management, service operations and service computing research. Based on this investigation, we identified relationships between the foundational concepts and visualised this structure in a conceptual model (in the form of a UML class diagram). Figure 1 shows the developed model of the ten foundational concepts to explain the diversity and complexity of service systems: entity, resource, access right, ecology, interaction, value proposition based interaction, governance mechanism based interaction, outcome, measure, and stakeholder [9].

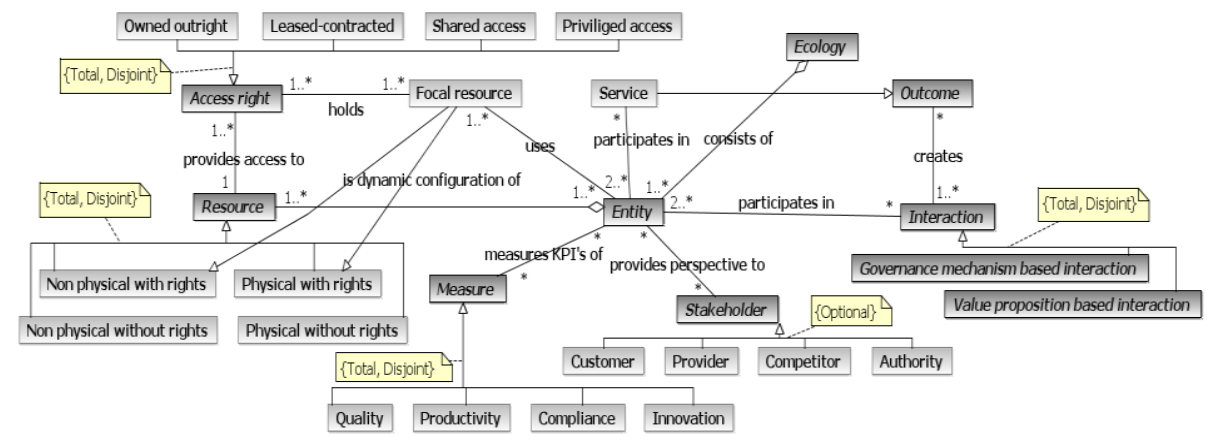

Fig. 1. UML Class diagram of the service systems worldview [7]

The ISPAR model deals with some of these concepts. It is a prescriptive model that considers all possible interactions and their corresponding outcomes between different service system entities. As there exists a great variety of different types of service interactions, the ISPAR model makes abstraction of this complexity by categorizing interaction episodes according to their outcome [10]. By mapping actual sequences of interactions onto the model, it becomes possible to evaluate a service system's quality (i.e., a specialisation of measure in Fig. 1). Quality can be expressed as the ratio of successful service outcomes to all other interaction outcomes of a service system. Moreover, the ISPAR model permits the mapping of (service) interactions of every possible kind of service system [11]. It is suited for typical value proposition based interactions between provider and customer which assume a value proposition that indicates how the interaction will lead to mutual value co-creation (i.e., what is called service in Fig. 1). However, it also provides a manner to model the outcomes of so called governance mechanism based interactions which occur in the context of collective interest i.e., when the interaction is regulated by a governing body like auctions or court cases [6]. 
To show the ten possible interaction episodes and outcomes, the ISPAR model is represented as a branch model (Fig. 2) [8]. Realization (R) is the most desired outcome. In this case the value proposition is successfully proposed, agreed upon and realized, and the outcome is mutual value co-creation.

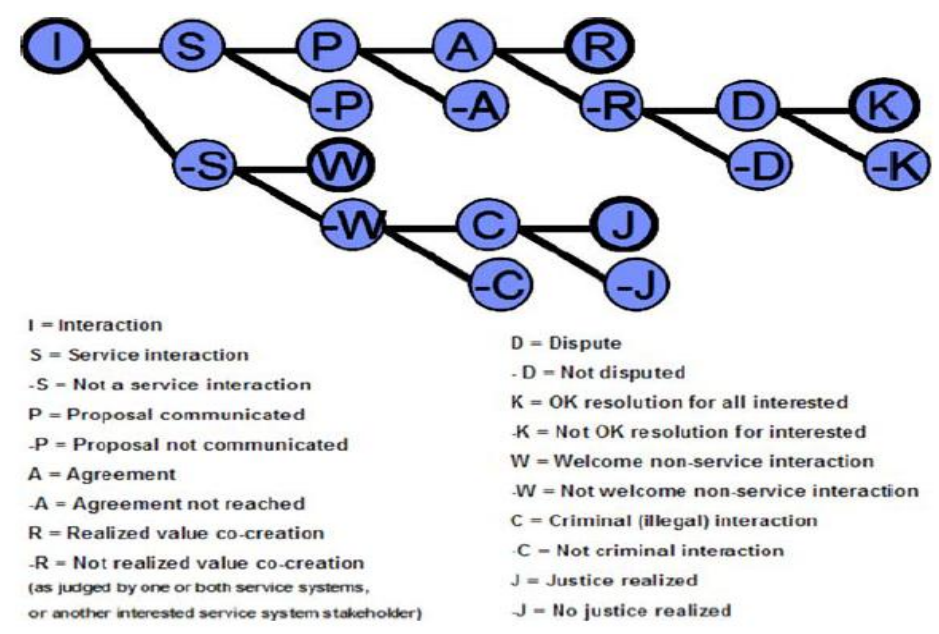

Fig. 2. The ISPAR model of service system interactions [8]

To reach outcome $\mathrm{R}$ two service system entities have to engage in interactions (I) which classify as service interactions (S) during which a proposal has to be communicated $(\mathrm{P})$ and the service system entities have to reach an agreement about the service (A). If the service proceeds as agreed, it is said that the service is realized (R). However, the ISPAR model indicates that the service systems worldview is not a happy path theory but also takes into account other outcomes that deviate from mutual value co-creation. A service proposal may not be successfully communicated or understood by a service system entity (-P) or two service system entities may not come to an agreement about the proposal (-A). Another option is that mutual value co-creation is not realized as agreed. In this case a dispute may (D) or may not (-D) arise. A dispute can lead to two possible outcomes. Either the dispute is successfully resolved for all stakeholders $(\mathrm{K})$ or the proposed solution is not acceptable for at least one stakeholder (-K).

When an interaction doesn't qualify as a service interaction (-S), it can be welcome (W) e.g., when saying hello to a colleague at work. However, a non-service interaction can be unwelcome (-W) e.g., when a restaurant discovers that two clients have been assigned to the same table. If this non-service interaction is not a criminal act $(-\mathrm{C})$, the interaction sequence ends at that point. If it concerns a criminal activity (C) like theft, this can result in justice $(J)$ if the criminal is punished or in no justice (C) if the lawbreaker manages to escape.

As the aim of this paper is to provide service researchers with a clear service process model that enables the analysis and improvement of the service process, the interaction episodes that are composed of non-service interactions will be left aside. 
The service process model we aim at will thus only cover situations in which mutual value co-creation is the purpose of engaging into interactions with other service system entities.

\section{Evaluation of the ISPAR Model}

Although the ISPAR model gives a comprehensive overview of the possible interaction sequences between two service system entities, the model does not serve as a good process model. Overall, the model lacks clarity and structure which makes it difficult to analyse service processes. We can identify several obstacles to the use of the ISPAR model as a normative service process model.

First, a good process model should emphasize all important activities that take place during the process. However, in the ISPAR model the propose and agree activities present a necessary (even if sometimes implicit), but often (though not always) a relatively minor part of the service process, while the realize activity comprises in many cases the main part of the service process. We believe that the realize component of the model is not specific enough and doesn't show the complexity of the realization of a service. If a company has a maintenance contract for the elevators of a building, the service realization interactions may be spread over several years and range from the monthly maintenance to a phone call from the sales department to extend the contract. As the type of services performed can differ strongly, the realize activity should be further refined.

Second, according to the ISPAR model a service proposal is very concrete and direct e.g. a service contract which is signed by both provider and customer. However, by using this limited view on proposals, a lot of potential service interactions are excluded from the analysis. A television commercial for a university could serve as a first proposal from that university to potential students, which are at the moment of broadcasting not individually identified and maybe not even aware of the service offer. We believe that a broader interpretation of the propose activity, i.e., not necessarily involving two explicitly identified service system entities that purposefully interact and are both aware of the service need and offer, could enable a more complete analysis of service processes.

Third, Spohrer and Kwan state that the ISPAR model shows service system interaction episodes which describe the sequence of activities that might be pursued by two interacting service system entities [11]. However, a few elements indicate that the ISPAR model may not be suited to describe the sequence of activities. Only the propose $(\mathrm{P})$, agree $(\mathrm{A})$ and realize $(\mathrm{R})$ nodes of the model are real activities (where $\mathrm{R}$ is at the same time an outcome). The interact (I) node has no real meaning other than being the source of all further offspring. The $\mathrm{S}$ and $-\mathrm{S}$ nodes describe types of interaction episodes, i.e., sequence of service or non-service interactions. The ISPAR model thus mixes the overview of possible outcomes with the actual process flow.

Fourth, in the ISPAR model every path leads to a different outcome. However, we believe it is possible that the same outcome is reached through different paths. We use the example of a consulting service to clarify our point. A consulting firm makes a 
proposal to a customer $(\mathrm{P})$ and reaches an agreement with that customer about this proposal (A). After fulfilling the proposed services, the consulting company invoices the customer. If the customer pays as agreed, mutual value co-creation is reached (R). However, if the customer does not pay, the outcome according to the ISPAR model would be -R. In an attempt to solve this problem (D), the consulting firm would send a reminder to the customer. If the customer pays the invoice after receiving the reminder from the provider $(\mathrm{K})$, mutual value co-creation is still reached. So in that case, outcome $\mathrm{K}$ is the same as outcome $\mathrm{R}$. In a good process model, these two paths would lead to the same end state. The same goes for the process nodes -P and -A. Although these nodes are outcomes in the ISPAR model, we argue that a badly communicated proposal can be set right by the decision to reiterate the proposal episode. Thus, the service process can still have a successful outcome. However, this cannot be read from the ISPAR model as it doesn't provide any return paths.

\section{Proposed Improvements for the ISPAR Model}

To propose improvements for the ISPAR model, we will formulate some ideas or strategies to counter each of the comments above. For the first tree comments, we evaluate two established service process frameworks. The first framework is a part of Alters' work system method which is a business-oriented system analysis and design tool [12]. The work system framework uses nine basic elements to provide a system view of the organisation [12]. Next to this work system framework, Alter proposes the service value chain, which elaborates the work system framework with serviceoriented insights [2]. It presents a two-sided view of the service process as the service is coproduced by customer and provider. It shows the different steps that should be executed in a service process. Alter shows the different kinds of interactions that emanate from a value proposition (figure 3). First, customer-provider contact is based on awareness. The provider should create awareness among customers about the existence of the service. The customer should become aware of a need that has to be filled. Next, provider and customer will engage in a negotiation about commitment to the service. The ISPAR model of the service systems worldview also recognizes these two types of interaction (i.e., proposal and agreement) which show how the service process is initiated, but as already mentioned does not further distinguish between different types of interaction that occur when the rest of the service process is executed (i.e., realisation). The service value chain model further defines these interactions or service encounters. The customer makes a service request which is handled and fulfilled by the provider and the customer participates in this fulfilment. Finally, both customer and provider follow up the handling of the service.

The second framework is the service ontology based on the DOLCE upper-level ontology of Ferrario and Guarino [13]. As can be seen in figure 4, a service is conceived as a complex event with five main parts: service commitment, service presentation, service acquisition, service process and service value exchange. A key concept in the service ontology is the commitment of an agent to guarantee the execution of a service at a certain place and time. The authors strongly focus on 
commitment which they consider as the core of a service. However, commitment here has a different meaning than commitment defined by Alter. Here commitment implies more than just agreeing to a value proposition. A value proposition is usually the result of negotiations between provider and customer. Therefore the customer has already decided he wants a certain service. Service commitment according to Ferrario and Guarino means the willingness to perform a service on the side of the service provider without needing the involvement of the customer. This implies that service can exist even before the occurrence of interactions between provider and customer. So, the commitment of the provider to guarantee the production of a service content is the first step in the service process.

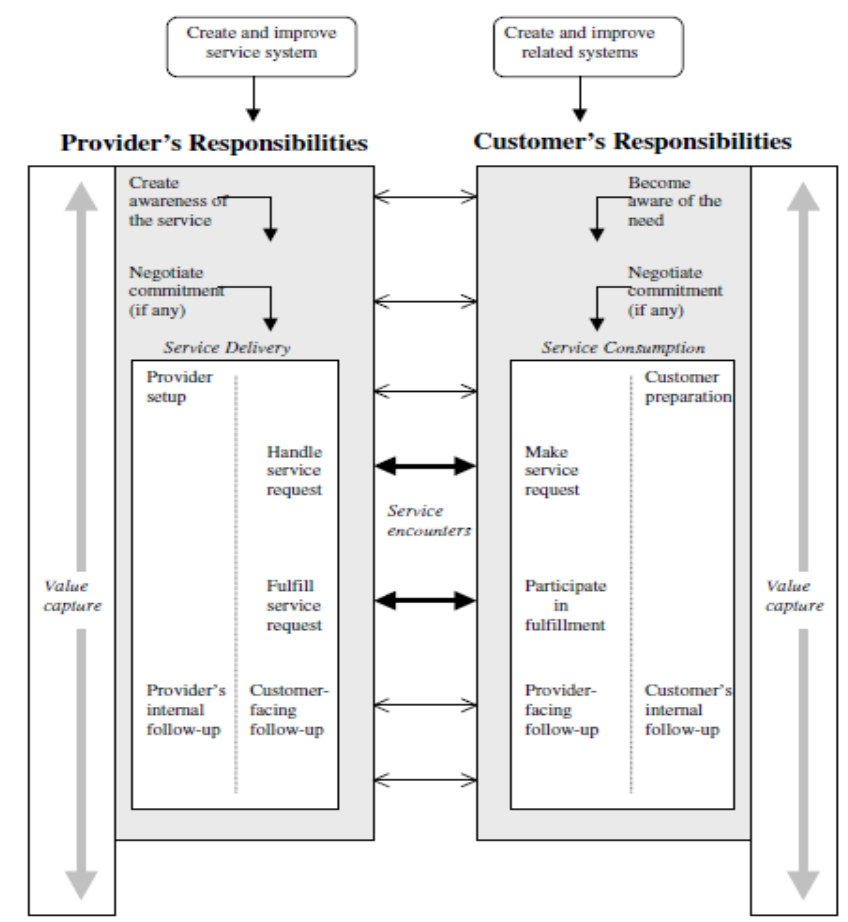

Fig. 3. Alters' service value chain framework [14]

Nevertheless, commitment is not sufficient to initiate the actual service execution as it only indicates willingness on the side of the provider. Hence, a triggering event is included. Provider entities should be notified of the occurrence of this event in order to know when the service should be executed. After the occurrence of the triggering event, the provider should bundle his services and present them to the customer. Then, service acquisition takes place at the side of the customer. After negotiating the service offer, the provider produces the service content. In order to produce the service, both customer and provider should sacrifice something e.g. the provider sacrifices time and effort into realizing the service while the customer has to sacrifice money and possible other resources like his time. 


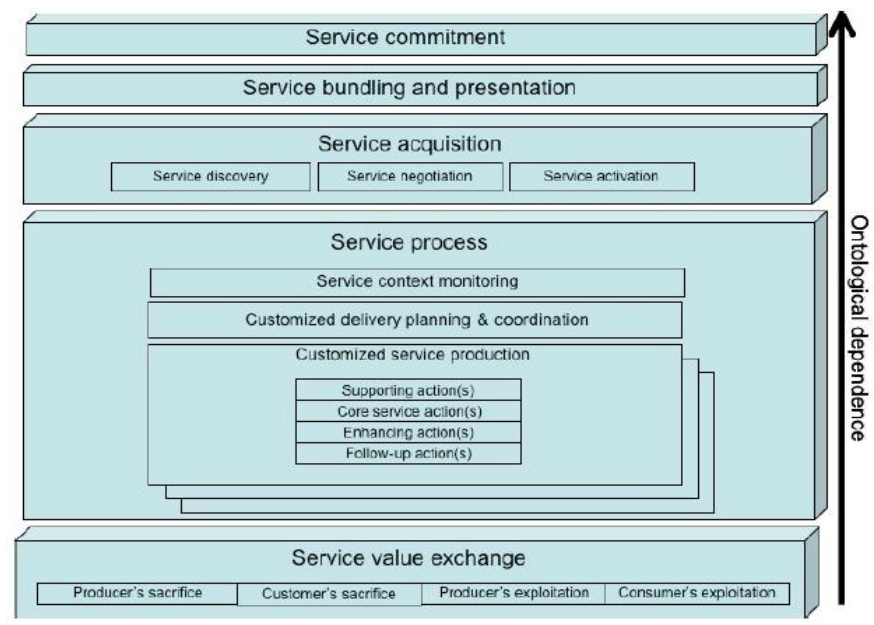

Fig. 4. The layered structure of service activities of the service ontology [13]

In our first critique on the use of the ISPAR model as a normative service process model, we suggested that the realise activity should be elaborated. Possible improvements can be found in the service value chain of Alter which identifies three different steps. First, the customer has to make a request which is handled by the provider. We believe this step may be important as agreement about a service does not always mean that the service is realized immediately. Next, customer and provider participate in the fulfilment of the service. Finally, customer and provider engage in some follow-up activities. The service ontology of Ferrario and Guarino also provides us with some useful insights. The authors also indicate that service agreement doesn't automatically lead to service execution. The occurrence of a triggering event is seen as a signal for initiating the service. However, the triggering event doesn't always have to be a customer request. For example, it could also be snowy weather which activates a snow removal service.

The second obstacle that we identified dealt with the interpretation of the propose activity. We notice that the propose activity is defined differently by the various service process frameworks. As already mentioned, in the ISPAR model a service proposition is very concrete and direct. Both the service value chain framework of Alter and the service ontology of Ferrario and Guarino provide us with a broader view of the proposal concept. We note that Alter uses a broader definition as the creation of awareness can also be done by broadcasting a commercial on television. Ferrario and Guarino introduce the concept of commitment which also indicates a broader understanding of the propose activity. According to the service ontology a fire department makes a commitment by simply existing and being prepared to provide help in case of a fire. Therefore the proposal is already done. However, as the service ontology of Ferrario and Guarino has a different definition of service which doesn't match the vision of the service systems worldview (see [7] for a comparative analysis of service definitions), we choose to adopt the interpretation of Alters service value chain. According to Ferrario and Guarino service equals commitment. We believe that 
this vision is suited for governance mechanism based interaction e.g., a fire department, but doesn't account for value proposition based interactions that are typically found in business, e.g., the mere existence of a kiosk doesn't commit the kiosk owner to sell newspapers to customers passing by.

The third comment stated that the ISPAR model mingles activities with outcomes. This is confirmed by looking at the service value chain framework of Alter and the service ontology of Ferrario and Guarino. Both frameworks roughly identify a propose, agree and realize episode. Interaction and service interaction are not part of the models as separate activities. Alter indicates that each contact between customer and provider e.g. interaction is a service encounter. This confirms our statement that every propose, agree or realize activity requires one or more interactions [5]. We can conclude that the ISPAR model should be redefined so that activities and possible outcomes or states of the system are separated from each other. To model the service process we propose the use of an EPC process model [15]. The EPC technique is a well-known Petri Net based process modeling technique. The basic building blocks of an EPC are events and functions. Functions describe an activity or task that leads from one event to another. An event describes the state of the process at a certain moment. In an EPC functions and events alternate each other. A Function is represented by a rectangle and an event by a hexagon. The events and functions can be connected through logical operators as XOR, IOR and AND.

To tackle the fourth comment we propose to change the representation of the ISPAR model. The service process model should be built in such a way that on the one hand paths which lead to the same end state are aggregated at some point in the process model and on the other hand return paths are provided to restore the service process in case of failure. The new representation of the service process model i.e., the EPC, provides us with the opportunity to incorporate this feature into the model.

\section{$5 \quad$ Service Process Model}

Figure 5 shows our proposal for a normative service process model based on the ISPAR model. In this model three possible outcomes can be identified: service aborted, service successfully ended, and service not successfully ended. All possible interaction paths in this service process model will eventually end in one of these three final states. As explained in section 4, we have chosen to work with an EPC representation of the service process model. The model allows us to separate functions (or interactions) from events (including ISPAR outcomes). All ten interaction episodes from the ISPAR model are included in the EPC..

The model starts with the event 'customer is aware of service need or offer'. This event accounts for both a push scenario in which the customer seeks a provider to fulfil a service need as a pull scenario in which a provider persuades the customer that a certain service might be useful. In both scenarios the provider possesses resources or access rights to resources that the customer needs or wants. This is in fact the reason for all service interaction. Customers become aware of a certain need or want but do not possess the necessary resources. Therefore a service process is initiated by 
the customer (push scenario) or the provider (pull scenario) in which all kind of resources are traded. Not only technology or natural resources but also information or competences are resources a provider might possess.

After this first event, which is the starting point of any service process depicted with our model, the activity 'propose service interaction' is performed. As explained above, we choose to adapt the service proposal interpretation of Alter in which a proposal is not narrowly defined, but can be anything that will eventually lead to an agreement between two interacting service system entities. If this activity fails and the service proposal is not successfully communicated or understood, this can lead to the outcome 'service aborted'. However, unlike the ISPAR model, our service process model provides a return path. This return path makes it possible to decide to revise and reiterate the service proposal.

If the proposal is successfully communicated and understood, the two service system entities can move on to 'agreeing to the service proposal'. Again, in case of failure, the service process can be aborted at this point or the service system entities can decide to revise the agreement. After an agreement about the service proposal is reached, the service execution should be initiated. The initiation signal which is mentioned in the service process model, can be compared to the triggering event in the service ontology of Ferrario and Guarino. However, the initiation signal could be a signal given by the customer or the provider or the occurrence of an event that starts the service realization. If the initiation signal is not sent or received, the service system entities could decide to revise the initiation signal. This return path provides an opportunity for the service system entities to choose a new initiation signal or detection method. If the initiation signal is not revised, the service is aborted.

If the first three activities (propose service interaction, agree to service proposal, and initiate service execution) in the process model succeed without problems, the service realization activity can start. This is the core activity of the model as this is the execution of the service content as defined by the agreement. The outcome of this activity is judged by both service system entities through different measures. If the service is successfully realized, both service system entities perform follow-up activities. In this model, the follow-up activities are seen as internal activities, performed by both service system entities separately. However, if these follow-up activities are a part of the agreed upon service proposal e.g. the installation of an elevator with a maintenance contract for the next 5 years, they should be looked at as a part of the service realization activity.

The service realization is not successful if one of the service system entities is not satisfied with the outcome of the service realization. This entity may decide to dispute the service outcome. If the service outcome is not disputed, the outcome of the service process is 'service not successfully ended'. However, if one of the service system entities decides to dispute the service outcome, the nature of the interaction changes. All previous interactions are value proposition based interactions i.e., based on the value proposition to which both customer and provider agreed. Here, we see a shift towards governance mechanism based interaction. 


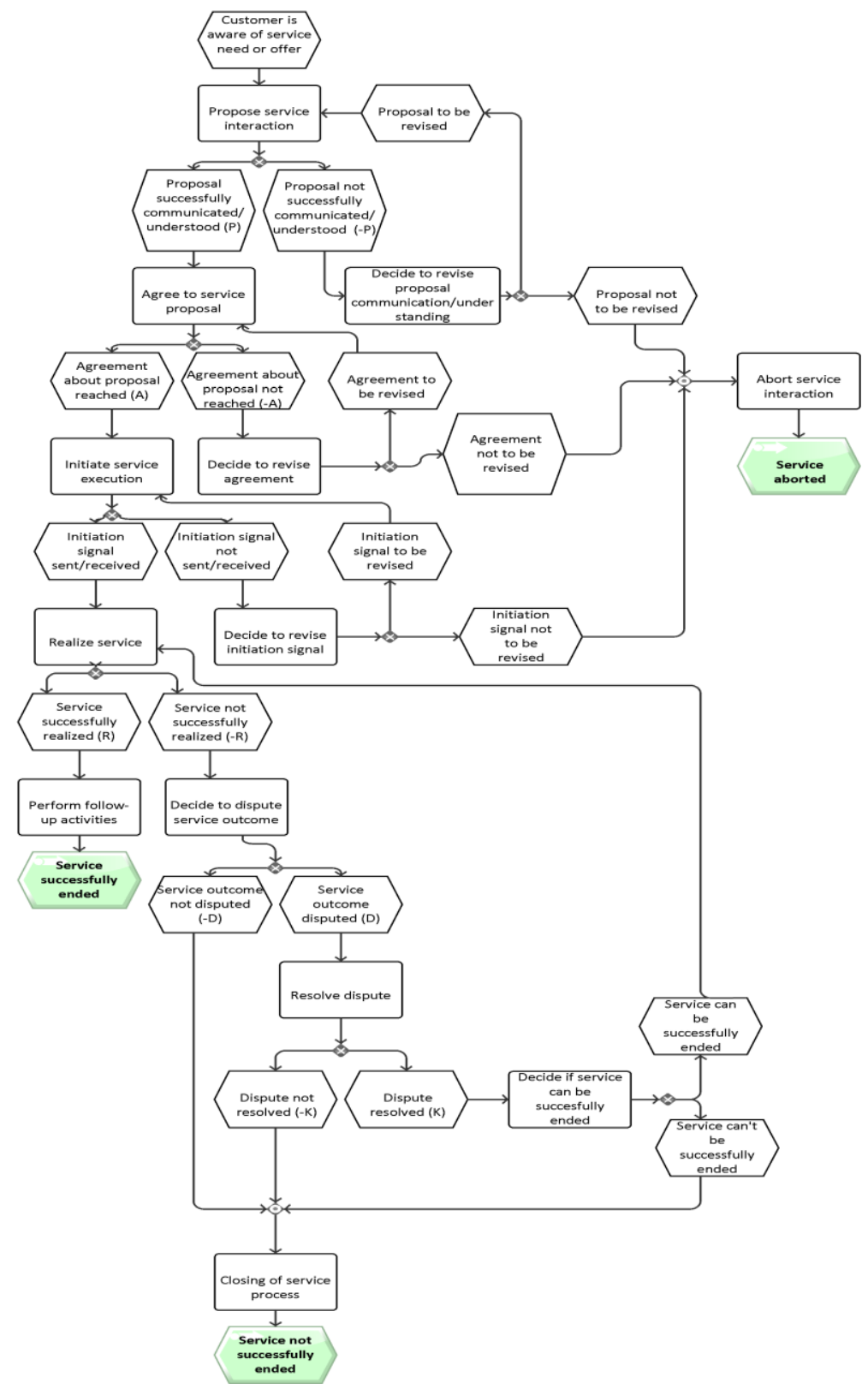

Fig. 5. EPC representation of service process model

In case of dispute between two entities, the interaction will probably be regulated by a governing body like a mediation service or a court case. If the service system entities do not succeed in resolving the dispute, the outcome is still 'service not successfully ended'. Resolving the dispute provides a return path to the 'realize 
service' activity. However, a solved dispute doesn't always mean that the service can be ended successfully. If a judge decides that an amount of money due by the customer is remitted, the dispute is solved but from the perspective of the provider this doesn't mean that the service can be ended successfully. To have a successful service ending, all stakeholders should be satisfied with the service outcome.

\section{Demonstration of Service Process Model}

To evaluate the service process model, we demonstrate three service examples which strongly differ from each other [16]. The advantage of this approach is that each example can be seen as the representation of a category of services that can be modeled in a very similar way.

The first example, a business lunch, is a type of service in which the exchange of physical resources forms an essential part of the service process. Figure 6 shows the EPC of a business lunch. The EPC shows that the service is not successfully ended as the customer didn't receive the meal he ordered. After a complaint of the customer with the restaurant owner, it is decided that the customer doesn't have to pay the meal and the dispute is settled In the ISPAR model this would equal service outcome K. However, compared with the ISPAR model, the example shows a few improvements. First, as can be seen from the EPC, the realize activity has been divided into the actual realization of the service content i.e., the cooking of the meal and serving it to the customer and the activity that initiates this service realization i.e. the communication of the order of the customer to the cook. Therefore the EPC gives a more complete overview of the service process. Due to this division, it becomes easier for the provider i.e., the restaurant owner, to determine the cause of the unsuccessful service delivery. Second, the model shows an unconventional proposal activity. The customer reads a lunch offer of a restaurant in a magazine. The advertisement states that a reservation is not needed. The example clearly illustrates a push scenario in which the customer initiates the service process. Although this kind of service proposal is not included in the ISPAR model, the advertisement categorizes as a service proposal from the provider to the customer. Third, due to the EPC representation form, activities are clearly separated from outcomes. Each activity is followed by a certain state which the determines the eventual outcome of the service process.

The second example shows a money investment service. In this case there is no physical exchange. The service is limited to a more abstract form of value co-creation. A bank notices a large amount of money on a customer's account and proposes the customer to invest the money. The different investment possibilities are discussed during an appointment but an agreement is not reached. The customer then decides to make a second appointment, but again no agreement is reached and the service process is aborted. Figure 7 shows the EPC model. This example also demonstrates how the use of EPC enables a clear distinction between outcomes and activities. Moreover, the model shows how a customer or provider can attempt to restore the service process after a failed agreement activity. The customer is not satisfied with the 
proposed investment rates and thus an agreement is not reached. The EPC provides a return path through which the customer can reiterate the agreement activity.

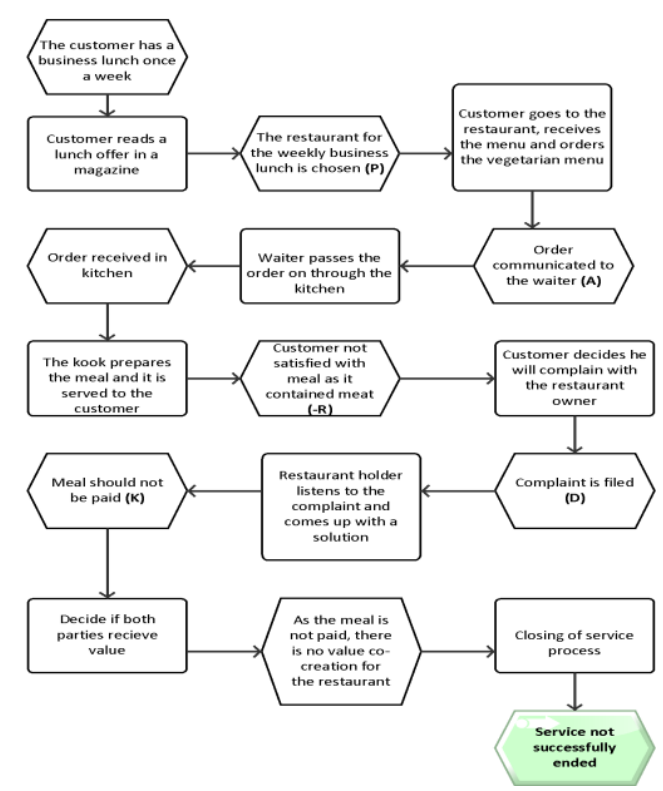

Fig. 6. EPC of business lunch

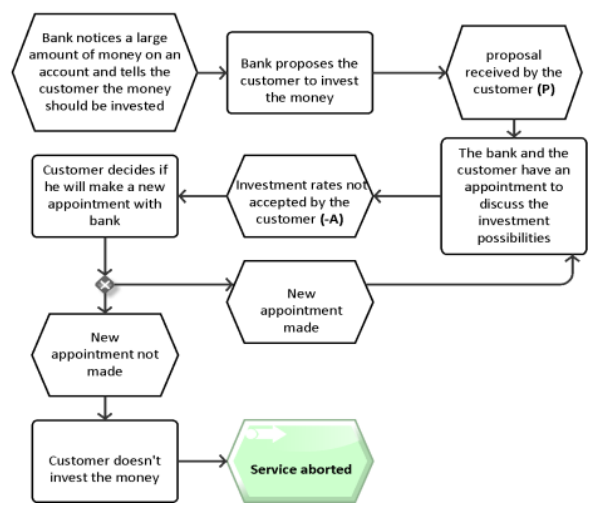

Fig. 7. EPC of a money investment service

The third example, an online newspaper service, doesn't include a physical exchange either. Moreover, there is no direct physical contact between the customer and the provider. Figure 8 shows the EPC which represents the category of online services. In this particular example the service outcome is mutual value co-creation (R) i.e., the service process is successfully ended for both the customer as the provider. However, as the proposal was not immediately understood by the customer, a return path had to be used. After calling to the customer service, the customer 
decides to revise the service proposal. After a second reading, the customer is willing to agree to this proposal. By analyzing the model the newspaper company could come to the conclusion that the terms of subscription are not clear enough. Based on this observation the newspaper could decide to improve the subscription terms or, to invest in an extra telephone operator to answer questions of confused customers in a more efficient way. Just as in the first example, the new division of the realization activities becomes clear. Before the actual service realization, an initiation signal is needed. In this case this is a confirmation email from the provider stating that the customer has access to the online articles. The downloading and reading of the articles represents the actual service content realization. When the contract expires, the newspaper performs some follow up activities such as propose the customer to extend his subscription.

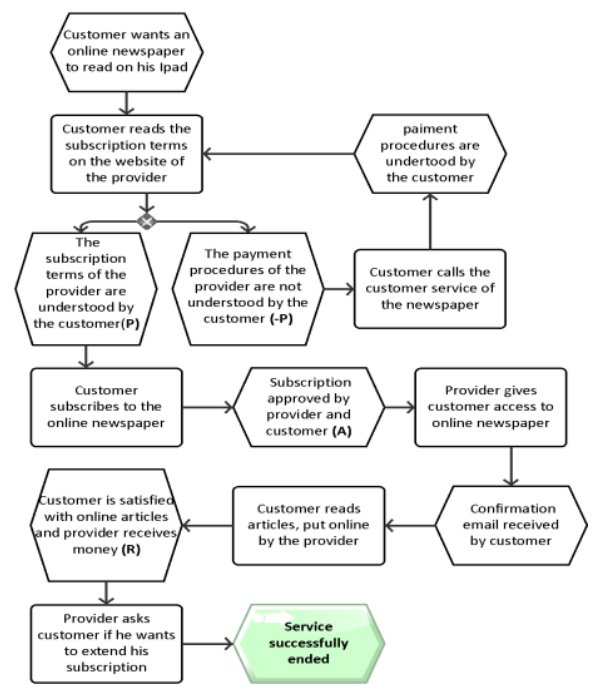

Fig. 8. EPC of an online newspaper service

\section{Conclusion and Future Work}

In this paper we investigated whether the ISPAR model could serve as a good service process model. Our research points out four shortcomings of the ISPAR model from which we conclude that the model in itself is not sufficient as a process model and needs elaboration with several elements, some of them handed by other service process frameworks. The new service process model includes all important elements of is the ISPAR model while adding elements of two alternative frameworks.

Future research may develop in two directions. First, the model should be elaborated such that an initiation signal can be given and received more than once. In the proposed service process model we assumed that this initiation signal had to be given only once. However, in some service situations such as a maintenance contract, the service realization might be caused by a long iteration of initiation signals. This is 
not incorporated in the current model and could be an interesting point of elaboration. Second, in order to fully realize the goal of integrating a normative service process model into the service systems worldview, a mapping of the service process model onto the ten foundational concepts defined by the service systems worldview is needed. It seems only logical that the description of how a service system is structured and the description of how a service system behaves are linked together in one conceptual model of service systems.

\section{References}

1. Vargo, S.L., Maglio, P.P., Akaka, M.A.: On value and value co-creation: A service systems and service logic perspective. European management journal 26, 145-152 (2008)

2. Alter, S.: Service system fundamentals: Work system, value chain, and life cycle. IBM Systems Journal 47, 71-85 (2010)

3. IfM, IBM: Succeeding through service innovation: a service perspective for education, research, business and government. University of Cambridge Institute for Manufacturing, Cambridge (2008)

4. Chesbrough, H., Spohrer, J.: A research manifesto for services science. Communications of the ACM 49, 35-40 (2006)

5. Poels, G.: A Conceptual Model of Service Exchange in Service-Dominant Logic. Lecture Notes in Business Information Processing: Exploring Services Science 53, 224-238 (2010)

6. Spohrer, J., Kwan, S.K.: Service Science, Management, Engineering, and Design (SSMED): An Emerging Discipline-Outline \& References. International Journal of Information Systems in the Service Sector (IJISSS) 1, 1-31 (2009)

7. Lemey, E., Poels, G.: Towards a Service System Ontology for Service Science. In: Full paper accepted for the 9th International Conference on Service Oriented Computing (ICSOC 2011). Springer, (2011)

8. Spohrer, J., Vargo, S.L., Caswell, N., Maglio, P.P.: The service system is the basic abstraction of service science. In: 41st Hawaii International Conference on System Sciences (HICSS), pp. 104-104. IEEE, (2008)

9. Spohrer, J., Maglio, P.P.: Service Science: Towards a Smarter Planet. In: Salvendy, G., Karwowski, W. (eds.) Introduction to Service Engineering. John Wiley \& Sons (2010)

10.Maglio, P.P., Vargo, S.L., Caswell, N., Spohrer, J.: The service system is the basic abstraction of service science. Information Systems and e-business Management 7, 395-406 (2009)

11.Spohrer, J., Anderson, L.C., Pass, N.J., Ager, T., Gruhl, D.: Service science. Journal of Grid Computing 6, 313-324 (2008)

12.Alter, S.: The work system method: connecting people, processes, and IT for business results. Work System Press (2006)

13.Ferrario, R., Guarino, N.: Towards an ontological foundation for services science. Future Internet-FIS 2008 152-169 (2009)

14.Alter, S.: Seeking Synergies between Four Views of Service in the IS Field. (2008)

15.Scheer, A.W., Thomas, O., Adam, O.: Process Modeling using Event Driven Process Chains. Process Aware Information Systems 119-145 (2005)

16.Roelens, B.: Een Service Science persfectief op bedrijfsmodellering. Master Thesis. Ghent Universtiy, Ghent (2011) 